\title{
Smart City: Convergent Socio-Cyber-Physical Complex
}

\author{
Andrey Volkov* \\ Moscow State University of Civil Engineering, Yaroslavskoe shosse, 26, Moscow, 129337, Russia
}

\begin{abstract}
New development objectives of the country specify the special significance of the sectorial building academic and professional community in enhanced understanding and active involvement in the processes of transformation of traditional and in the formation of new areas of competences. Creation, facilities and infrastructure, the urban environment are becoming today the main area of meeting and concentration of high-tech areas of scientific progress. This article presents a new logical and conceptual model of the sequence of stages of creative activity, a new definition of the concept of "smart city" and "convergent socio-cyber-physical complex", original system technology layout of digital modeling of creative activity. The layout describes seven levels of digital modeling that correspond to six levels of connections formation: "plan" - "objective", "object" - "project", "process" - "time", "technology" - "economics", "system" - "resource", "complex" "convergence".
\end{abstract}

\section{Domain Area}

The President and the Government of the Russian Federation set new major tasks for the territorial, high-tech and social development of the country, the solution of which depends on the progress in research, the quality development of the education system, the creation and implementation of advanced technologies of creativity throughout the vast territory of our country.

Today, in the context of modern global challenges, an obvious acceleration of generation processes, an open distribution space and, as a result, an intense global competition of knowledge and technology, the particular importance of our industry, academic and professional community involves enhanced understanding and closed involvement in the transformation processes of traditional areas of competence and the formation of new ones, which right now, before our eyes determine strategic sustainability, technical and social progress of entire nations for decades to come.

It is the creation, the results of our work - the facilities and infrastructure, the urban environment and the environment of our life and activities in general are becoming the area of meeting and concentration of the results of the development of an enormous number of high-tech and brand new areas of technology and equipment, any of which separately,

\footnotetext{
Corresponding author: ChelyshkovPD@mgsu.ru
} 
although it forms its part of the "future", but does not correspond to the synergetic mission of their set of objective limitations of only their own private domain area. Even a truly global modern "digital" trend forms new strategic competences for the development of human capital assets only across technological and cognitive components, while the quality effects of solving such a problem are formed today based on its formulation and analysis in the socio-cyber-physical and convergent systems paradigm [1-3], the main target and functional emphasis of which are in the field of facilities, processes and results of creative activity, to be more accurate - in all its horizon, not limited to any one stage, but extended to their exhaustive sequence, including motivation, planning, design, creation, adaptation, use, transformation, and recycling of the constituent elements (fig. 1).

Adequate awareness of the nature and scope of the task in such a formulation is seriously hampered by the industry's traditionally conservative attitude towards the introduction of the latest advances in scientific-and-technological advance, which objectively limits its existing and future innovative potential. It should be noted that this situation is typical not only for our country. All over the world, construction, as a rule, is not classified as a high-tech industry in the real sector of the economy. On the other hand, it should be realized that a sustainable existence and, of course, the development of any state depends heavily on its infrastructure potential, which, in turn, hinges on the innovation potential, labor productivity and the integrated efficiency of the construction industry.

It should be noted that today there is active research in a number of promising branches of the industry [3-5,8], focused on the development of information (digital) modeling technologies which is the main integration entity that unites all stages of creative activity (see fig. 1).

Examples of possible forms of visualization of digital models are shown in fig. 2-5.

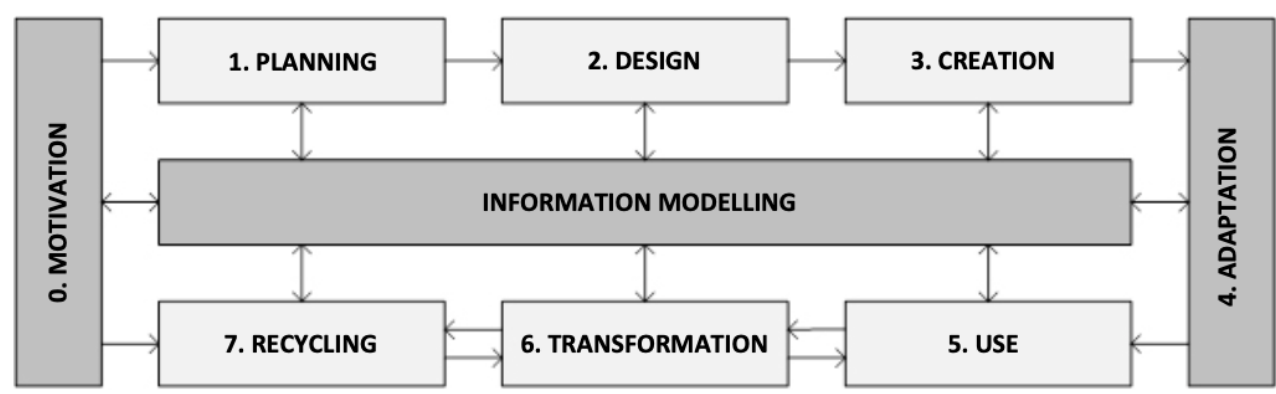

Fig. 1. Sequence of Stages of Creative Activity

The logical and conceptual model of the sequence of stages of creative activity is given in fig. 1. However, it is somewhat qualitatively expanded by the author in comparison with the well-known enumeration of stages of the life cycle of facilities (buildings, structures) repeatedly published in various sources referred and considered by the professional and expert community. The new meaning of the conceptual subject matter (technological concept) "smart city" predetermines the inclusion in the model of a special stage (stage 4 in fig. 1) with a focus on social adaptation of the perception of newly created (transformed) elements (objects) of creative activity by people and society. The need to highlight such a stage is determined by the dynamically growing acuteness and extent of the problems arising today as a result of the spread of globalization and the intensive development of scientific-and-technological advance across the man-made and social systems. In any big city it is, for example, transport, environment, availability of social services, comfort, safety, and so on. 


\section{Smart City}

Today, following not only a single, however, but a whole set of promising technological and social trends, quite often, in various aspects and at different levels, the concept of "smart city" is mentioned and is becoming increasingly part of the marketing and professional thesaurus. In fact, making up the consolidated response of the above mentioned trends, suggesting the formation of a new quality of life and human activity in the areas of its concentrated and long-term positioning only on the one hand, and having an equal share of completely new, including prospectively synergistic, technological and social, public and individual risks, on the other hand, the term "smart city" itself continues to remain virtually undefined. In other words, none of the existing, not only in our country, by the way, but in the world, definitions of this term are formally exhaustive, i.e. in fact, it makes it possible to compare the objects described with their help only on a limited set of attributes, each time original, without keeping the possibility of building and using a single, to the required degree universal of a system of technical regulation and regulation of the industry.

However, today this kind of situation, in general, is not critical because of the abovementioned conservative attitude of the industry to innovations, and the emerging tasks of assessing the actual potential of cities and settlements on this basis are already today more or less effectively solved depending on the goal-setting of such ratings. Considering the enormous scale of the subject area under consideration and the various qualitative and quantitative features of cities and settlements as appraisal objects, in most cases specialists use a universal set of parameters actual values of which are available at the level of state information systems, statistics and format surveys of target groups of the population. The main advantage of this approach is the direct contact of specific target values with the actual economy of the city.

However, it should be noted with satisfaction that research on this topic is becoming more and more popular all over the world, and in our country since the first academic publications 10-15 years ago [ 1 and others] the terms "smart building" and "smart city" are included in the documents of strategic planning of the highest level [7].

In 2012, for the first time, a universal formal definition of the concept of "intelligent building", including the absolute and design levels abstractions, the abstract definition of "intelligence quotient of buildings", expandable for any task of building applied theories and use in the practice of building design and management. The relevant formal foundations of the presented definitions are outlined, the prospects for the development of the designated direction in terms of the technical regulation of the industry are considered [2].

Within the framework of such a paradigm, a formal definition of a new conceptual entity (technological concept) "smart city" can be represented as follows.

"Smart City" is a convergent socio-cyber-physical complex, the management parameters processes of which are optimally adaptive to their own state space.

Or in a popular-science sense, a "smart city" is a city that is optimally flexible to human being and society.

At the same time, a "convergent socio-cyber-physical complex" is a finite set of open convergence systems, including functional components (elements, objects, computing resources integrated into the included physical processes), and their interaction, human being and society, allocated in accordance with a certain system goals on a specific time interval (fig.2). 


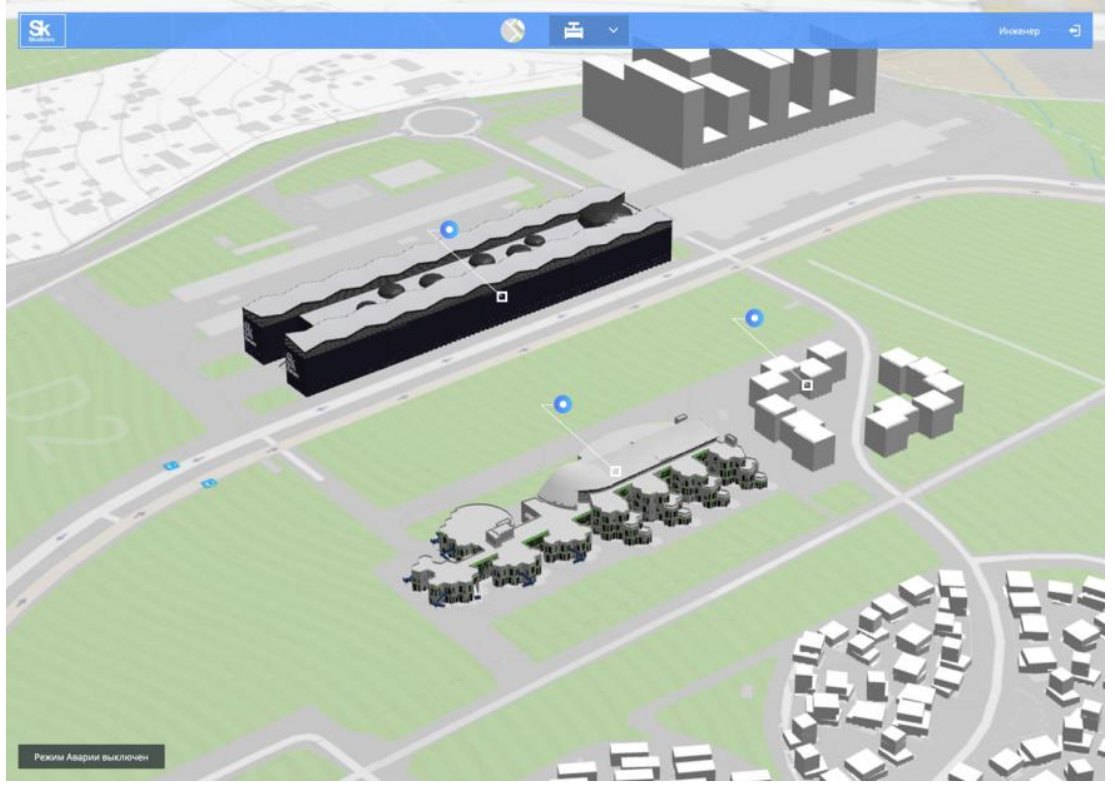

Fig. 2. Example of possible forms of visualization of digital models

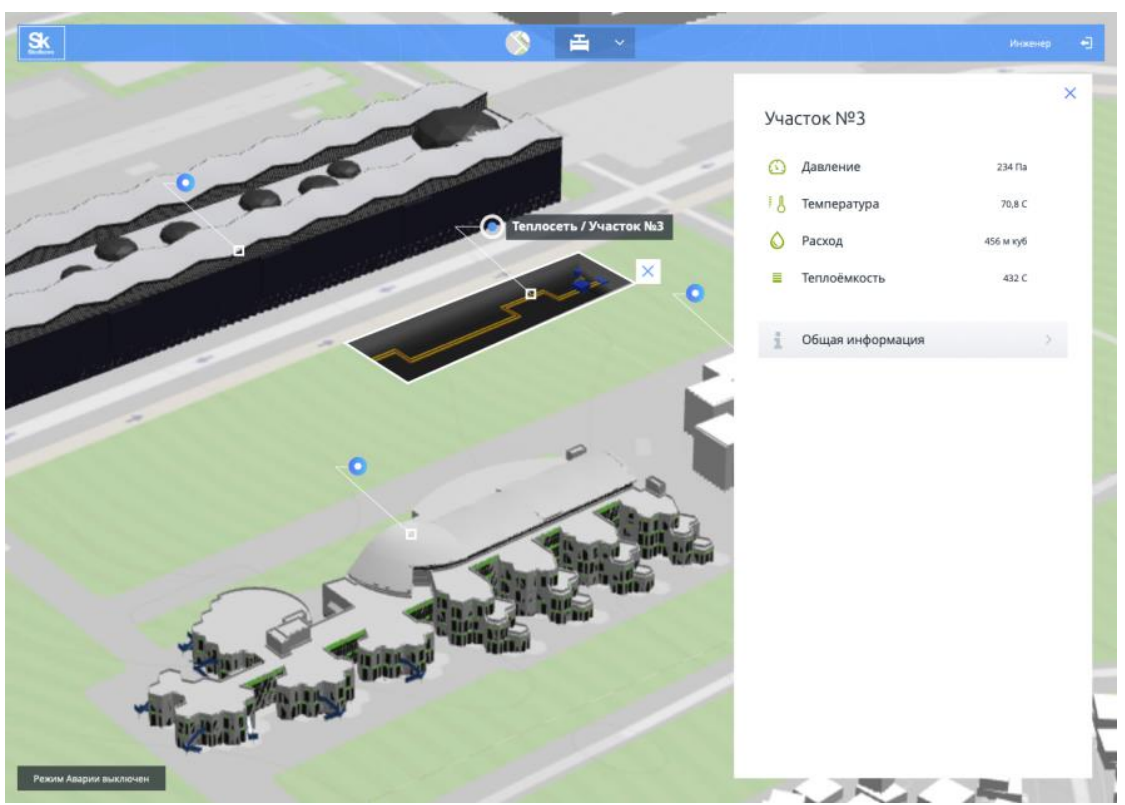

Fig. 3. Example of possible forms of visualization of digital models 


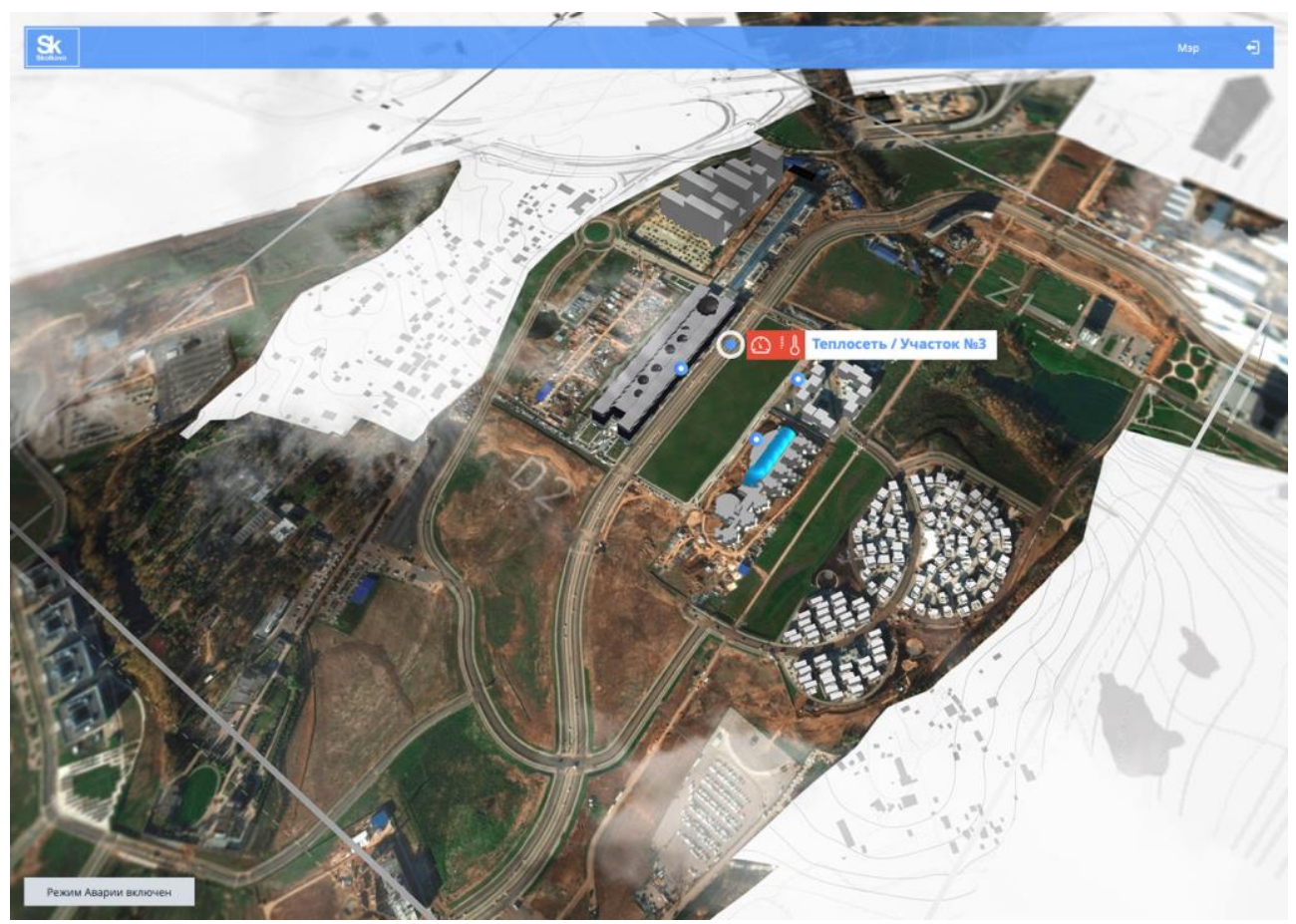

Fig. 4. Example of possible forms of visualization of digital models

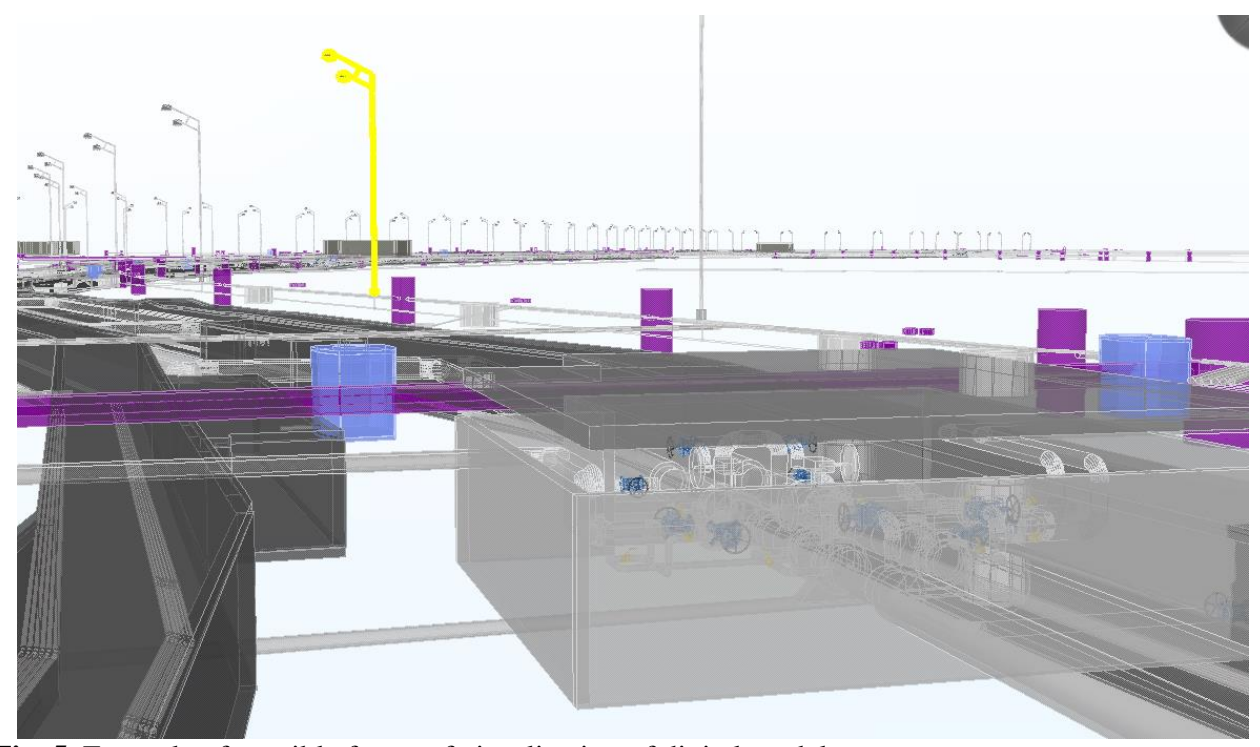

Fig. 5. Example of possible forms of visualization of digital models

In the following publications, we will certainly present the model foundations of the stated definitions, the paradigm of which, among other things, urgently requires some systematization of the modern view of the professional community regarding the "digital economy" and "digital modeling" of the construction industry and broadly speaking the field of creative activity [9-13]. 


\section{Conclusions}

1. A new logical and conceptual model of the sequence of creative activity stages is considered. The new meaning of the conceptual subject matter (technological concept) "smart city" predetermines the inclusion in the model of a special stage with a focus on social adaptation of the perception of newly created (transformed) elements (objects) of creative activity by people and society.

2. For the first time, a new definition of the concept "smart city" and a component definition of "convergent socio-cyber-physical complex" are presented. "Smart City" is a convergent socio-cyber-physical complex, the management parameters processes of which are optimally adaptive to their own state space. In the popular-science sense, a "smart city" is a city that is optimally flexible to human being and society. A "convergent socio-cyberphysical complex" is a finite set of open convergence systems, including functional components (elements, objects, computing resources integrated into the included physical processes), and their relationships, human being and society, allocated in accordance with a certain goals system on a specific time interval.

This work was financially supported by Ministry of Science and Higher Education of the Russian Federation (\#NSh-3492.2018.8).

\section{References}

1. A. Volkov "Smart buildings" - "smart city": from practice to theory J. Automation of buildings. 5. (2006)

2. A. Volkov Intelligence of buildings: formula J. Industrial and civil construction. 54-57, 3. (2012)

3. A. Volkov Cybernetics of the building system. Cyber physical building systems J. Industrial and civil construction. 4-7, 9. (2017)

4. A. Volkov Smart City: Convergent Socio-CyberPhysical Complex. J. Industrial and Civil Engeeniring, 4-11, 9. (2018)

5. V. Ilichev, V. Kolchunov, N. Bakaeva Training of experts in architectural and construction industry on the basis of the paradigm of biospheric compatibility $\mathrm{J}$. Industrial and Civil Construction. 9-17, 9. (2017)

6. Systems engineering / Edited by A. A. Gusakov. (M.: New millennium Foundation. 768, 2002)

7. Digital economics of the Russian Federation, Program. Government Decree of the Russian Federation dated 28/07/2017, No. 1632-p. 87 P. Electronic source: URL http://static.government.ru/

8. P. Chelyshkov Aspects of computer-aided design of cyber-physical building systems $\mathbf{J}$. Industrial and Civil Construction. 21-27, 9. (2018)

9. A. Volkov, , P. Chelyshkov, , Y. Grossman, A. Khromenkova, J. IOP Conference Series: Earth and Environmental Science, 90, 1 (2017) DOI: 10.1088/17551315/90/1/012203

10. A. Volkov, P. Chelyshkov, D. Lysenko, J. Proc. Engin. 833-837, 153 (2016) DOI: $10.1016 /$ j.proeng.2016.08.251

11. A. Volkov, A. Sedov, P. Chelyshkov, A. Doroshenko, J. Applied Mechanics and Materials 3231-3233, 580-583 (2014) DOI: 10.4028/www.scientific.net/AMM.580583.3231

12. A. Volkov, A. Sedov, P. Chelyshkov, E. Kulikova, J. Applied Mechanics and Materials 757-760, 584-586 (2014) DOI: 10.4028/www.scientific.net/AMM.584-586.757 
13. A. Doroshenko, J. MATEC Web of Conferences 05013, 112 (2017) DOI: $10.1051 /$ matecconf/201711205013

14. Chelyshkov, P. Use of BIM in Design of Standarrd Facilities / P. Chelyshkov, D. Lysenko // International Journal of Applied Engineering Research Volume 12. - 2017. No 24. - pp. 15119-15121

15. Andreeva, A. Management of parameters of the functioning of engineering systems of the building object based on algorithmic data analysis / A. Andreeva, P. Chelyshkov // IOP Conference Series: Materials Science and Engineering. - 2018. - V. 365. 022041. - doi: 10.1088/1757-899X/365/2/022041

16. Lysenko, D. The method of optimization of energy-efficient engineering solutions by varying criteria in CAD / D. Lysenko, P. Chelyshkov // IOP Conference Series: Materials Science and Engineering. 2018.- V. 365.- 022027. doi: 10.1088/1757899X/365/2/022027

17. Galkina, E., Kuzina, O. Building information model verification at the lifecycle stage of construction //Volume 365, Issue 6, 2018, No 062031, 21st International Scientific Conference on Advanced in Civil Engineering: Construction - The Formation of Living Environment, FORM 2018.

18. Ginzburg, A., Kuzina, O., Ryzhkova, A. Unified resources marking system as a way to develop artificial intelligence in construction // Volume 365, Issue 6, 2018, No 062021, 21st International Scientific Conference on Advanced in Civil Engineering: Construction - The Formation of Living Environment, FORM 2018. 